\title{
Viral infections as a cause of cancer (Review)
}

\author{
C. CARRILLO-INFANTE ${ }^{1,2}$, G. ABBADESSA ${ }^{1,3}$, L. BAGELLA ${ }^{1,2,4}$ and A. GIORDANO ${ }^{1,2}$ \\ ${ }^{1}$ Sbarro Institute for Cancer Research and Molecular Medicine, Center for Biotechnology, College of Science and Technology, \\ Temple University, Philadelphia, PA, USA; ${ }^{2}$ Department of Human Pathology and Oncology, University of Siena; \\ ${ }^{3}$ Oncology and Hematology Department, Istituto Clinico Humanitas, Rozzano (Mi); \\ ${ }^{4}$ Department of Biomedical Sciences, Division of Biochemistry, University of Sassari, Italy
}

Received January 16, 2007; Accepted February 22, 2007

\begin{abstract}
In order to promote carcinogenesis multiple factors must be orchestrated. The alteration of the cellular genome after a carcinogenic exposure may result in malignancy if apoptosis is prevented and the immune surveillance fails to eliminate the transformed cell. Infectious agents may exert these properties and transform a host cell. Viruses associated with human cancer are known as 'tumor viruses'. Most of them are capable of integrating into the host genome and have the ability to immortalize the target cell in order to allow their own replication. The infected cell expresses the viral genes, which are able to induce cell growth, proliferation and prevent apoptosis. This review focuses on Epstein-Barr virus, human papilloma virus, hepatitis $C$ virus, hepatitis $B$ virus, human herpes virus 8 and human T-cell leukemia virus, since they have been already established as causative agents of human cancer. An understanding of the viral replication mechanism may provide new targets for the development of specified viral therapy that may have an impact not only on viral infections but in human cancer as well.
\end{abstract}

\section{Contents}

1. Introduction

2. General aspects of viral oncogenesis

3. Human papilloma virus (HPV)

4. Hepatitis B virus (HBV) and hepatitis $\mathrm{C}$ virus (HCV)

5. Human herpes virus $8(\mathrm{HHV}-8)$

6. Human T-cell leukemia virus type-1 (HTLV-1)

7. Conclusion

Correspondence to: Dr Antonio Giordano, Sbarro Institute for Cancer Research and Molecular Medicine, Center for Biotechnology, Temple University, BioLife Science Bldg., Suite 333, 1900 N 12th Street, Philadelphia, PA 19122, USA

E-mail: giordano@temple.edu

Key words: tumor virus, cancer, oncogene, Epstein-Barr virus, human papilloma virus, hepatitis C virus, hepatitis B virus, human herpes virus 8 , human $\mathrm{T}$-cell leukemia virus

\section{Introduction}

Cancer is the final result of a number of genetic alterations occurring in a cell. These changes may alter the balance between proliferation and programmed cell death (apoptosis) mechanisms and transform the cell. Malignant transformation is divided into stages of initiation, promotion and progression (Fig. 1). Usually, there is a long latent period from the moment of carcinogenic exposure to the neoplastic transformation in which the somatic cell is allowed to proliferate while accumulating multiple genetic mutations that might lead to a disease in an individual. Inherited genetic alterations can occur in somatic and in gonadic cells, allowing their presence in future generations $(1,2)$. Multiple factors have been associated with the oncogenic process such as environment, lifestyle, host factors, infectious agents and inheritance. Understanding cancer etiology and risk factors is a useful tool to help identify high-risk populations, and improve screening procedures and preventive methods.

Among these risk factors, infectious agents may be one important preventable cause of cancer. Within this group, viruses are the most common agents involved in the pathogenesis of human cancer. In the past decades, viruses have played an important role in cancer biology, contributing significantly in our comprehension of cell signaling and growth control pathways that result in cancer. This insight has been achieved through the study of viral transforming properties. Consequently, viruses have been suggested as causative agents of human neoplasia. Recent estimates have shown that $17.8 \%$ of cancer cases are attributable to infectious agents and of these, $12.1 \%$ correspond to viral infections (Table I) (3).

\section{General aspects of viral oncogenesis}

Once a viral infection has been established, innate and adaptive immunity are activated in response, aimed to eliminate the infection. An acute inflammation is a short process that is usually protective for the host with the purpose of eliminating the pathogen. Chronic inflammation may result from an unresolved acute inflammation, due to failure in eradicating the pathogenic agent. Therefore, chronic inflammation may favor the persistence of the pathogen in the tissue for a prolonged period of time $(4,5)$. The infection itself usually is not enough 


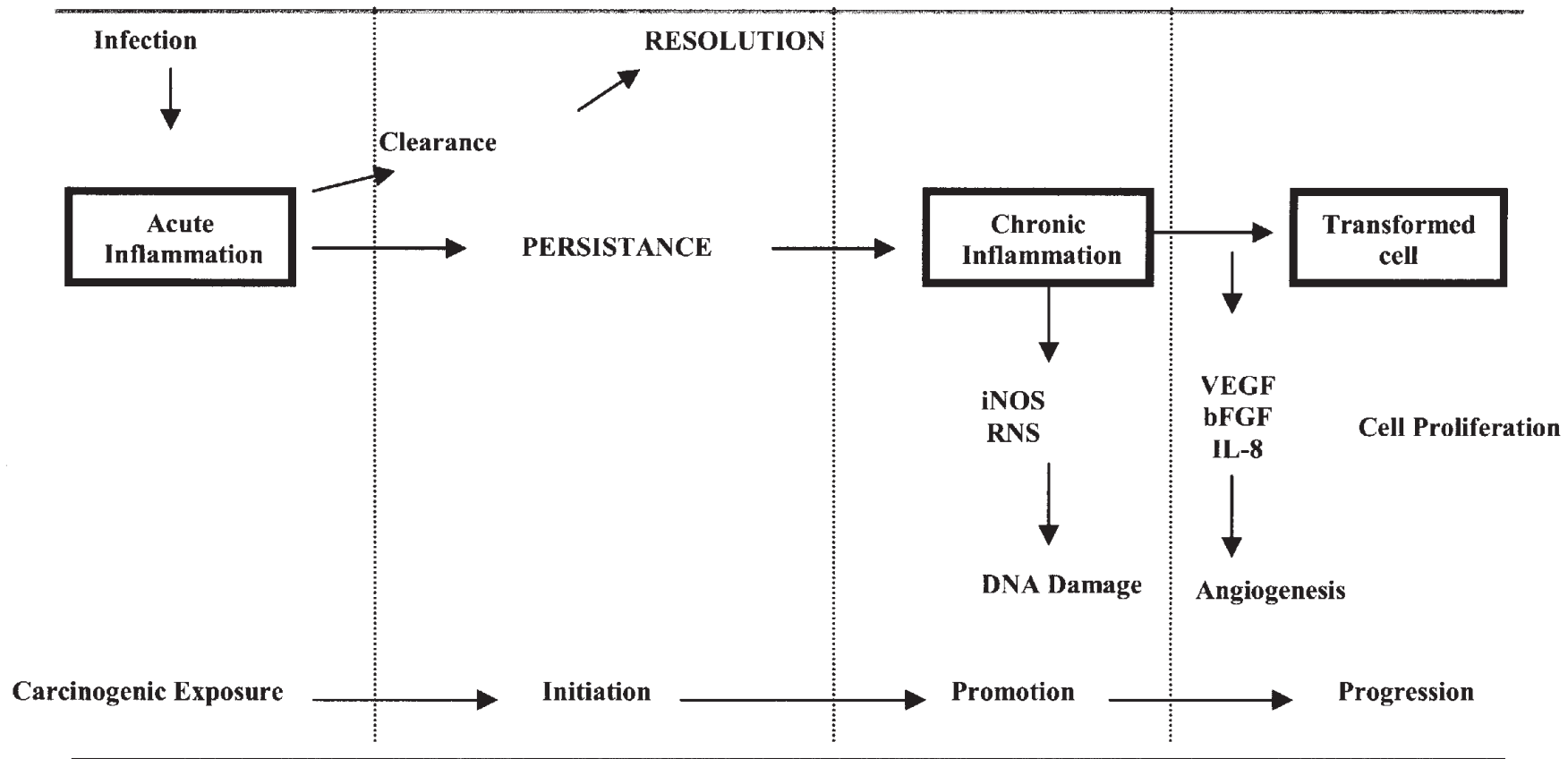

Figure 1. Sequence of events of infection/inflammation and cancer. Acute inflammation occurs, as the host's first response to eliminate an infection. Unresolved infection may result in chronic inflammation. Inflammation generates the production of iNOS and RNS, which are potent DNA-damaging agents causing genome mutations and instability. Chronic inflammation contributes to apoptosis and tissue generation with the promotion of microvessel formation and cell proliferation. This sequence of events corresponds to the stages of initiation, promotion and progression for cancer development.

Table I. Infectious agent-associated malignancy.

\begin{tabular}{lll}
\hline Viral agent & \multicolumn{1}{c}{ Route of infection } & \multicolumn{1}{c}{ Human cancer } \\
\hline EBV & Saliva & BL, NPC, NHL, PTD \\
HPV & Sexual & Cervical cancer \\
HCV & Sexual/post-transfusion/ & Hepatocarcinoma \\
& IV drug-user & \\
HBV & Perinatal/sexual & Hepatocarcinoma \\
HHV-8 & Sexual & Kaposi's sarcoma \\
HTLV-1 & Sexual/perinatal/ & ATL, HAM \\
& parenteral & \\
\hline
\end{tabular}

EBV, Epstein-Barr virus; HPV, human papillomavirus; HCV, hepatitis $\mathrm{C}$ virus; HBV, hepatitis B virus; HHV-8, human herpes virus 8; HTLV-1, human T-cell leukemia virus type-1. BL, Burkitt's lymphoma; NPC, nasopharyngeal carcinoma; NHL, non-Hodgkin's lymphoma; PTD, post-transplant-disease; ATL, adult T-cell leukemia; HAM, progressive myelopathy.

to create the proper environment for cancer formation. Factors such as host immunity and chronic inflammation play an important role in promoting the conditions for neoplastic cells to proliferate. In fact, chronic inflammation is supposed to be beneficial for the host by trying to clear the antigenic insult, but it has also been recognized as a factor that can promote carcinogenesis. A variety of inflammatory cells are activated during this process, releasing cytokines, chemokines and nitric oxide (NO) particularly, an inducible isoform of nitric oxide synthase (iNOS), and NO-derived reactive nitrogen species (RNS), which may be able to cause DNA damage and have a direct effect upon cell proliferation and neoangiogenesis (6-8).

Some viruses have the capacity to elude the immune system and remain latent. One way for them to achieve this objective is by inducing the regulatory $\mathrm{T}$ cells (Tregs), which physiologically cause immunosuppression to protect the host from a hyperactive immune response secondary to a chronic infection/ inflammation (9-11). These events might leave the host susceptible to either permit a virus to remain latent or to reactivate a latent infection (12). The mechanism to remain latent in the host depends on the type of virus. DNA tumor viruses such as HPV, EBV, HBV and Kaposi sarcoma herpes virus (KSHV) usually persist by either integrating in the host genome or by remaining episomally. RNA tumor viruses such as human T-cell leukemia virus type 1 (HTLV-1) and HIV are reversely transcribed into a double-stranded DNA, with a further integration into the chromosomal DNA (Fig. 2) (13). HIV has been indirectly associated with carcinogenesis; it induces a chronic state of immunosuppression, reducing immunosurveillance for neoplastic cells and increasing the risk of reactivation of latent viruses as well as the risk of acquiring new infections $(14,15)$. HCV is an RNA tumor virus which, in contrast with HTLV-1 and HIV, lacks the capacity to integrate into the host genome. As a consequence, $\mathrm{HCV}$ exerts its carcinogenic influence by damaging liver tissue through chronic inflammation. Tumor viruses may directly transform the cell by carrying oncogenes into a cell or by activating cellular proto-oncogenes. These viral-derived oncogenes can potentially interfere with normal cell function by producing transforming growth factors that deregulate growth control and proliferation, leading to malignant transformation 


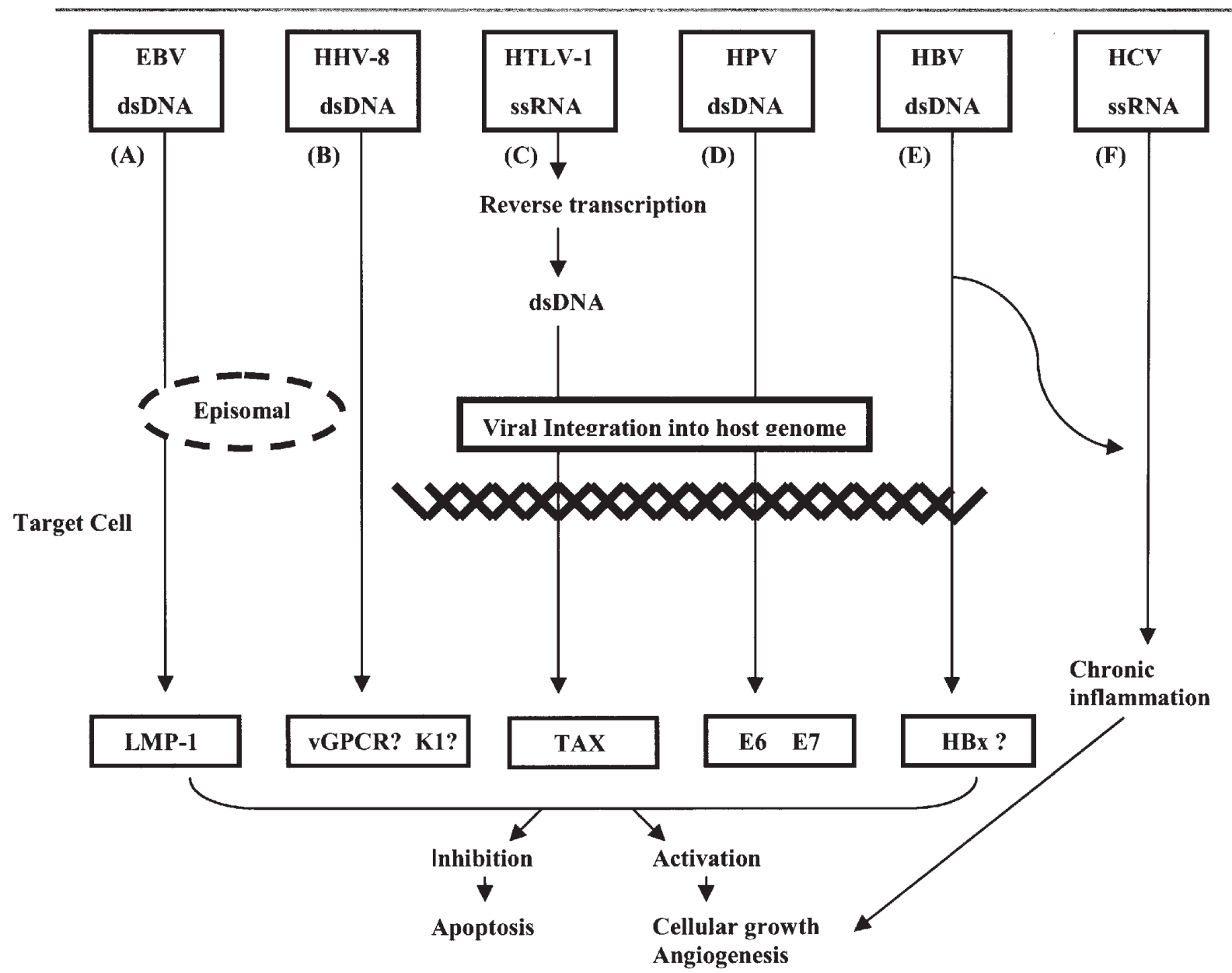

Figure 2. Mechanisms of oncogenesis. This figure illustrates the different oncogenic activity that tumor viruses have in order to promote their replication. Most tumor viruses have the ability to integrate into the host genome and express their viral oncogenic proteins, which disrupt cellular pathways in order to sustain their life cycle. (A) EBV, Epstein-Barr virus, has dsDNA, it remains episomally and encodes for LMP1 transforming protein. (B) HHV-8, human herpes virus-8, has dsDNA, It remains as an episome, it expresses vGPCR and K1 proteins among others, which have been shown to have transforming properties in vitro in mice. (C) HTLV-1, human T-cell leukemia virus type-1, has ssRNA which is reverse transcribed into dsDNA. It integrates into the host genome and encodes for the trans-acting factor tax, which is considered to be a transforming protein. (D) HPV, human papilloma virus, has dsDNA, it may remain episomally, but only from integrated genome are expressed E6 and E7 transforming proteins. (E) HBV, hepatits B virus, has dsDNA, it integrates into the host genome and produces the HBx protein whose transforming properties are still not clear, however HBV exerts its carcinogenic effect mainly through chronic inflammation. (F) HCV, hepatits $\mathrm{C}$ virus, has ssRNA, it does not integrate into the host genome, it exerts its carcinogenic effect through chronic inflammation.

$(16,17)$. DNA tumor viruses, in particular, carry oncogenes that target cellular tumor suppressor proteins such as p53 and $\mathrm{pRb}$ (retinoblastoma gene product), and are essential for viral replication and cellular transformation (18). All of these events might cause cell transformation, which may not necessarily mean cancer until a dysfunctional immune surveillance system is unable to prevent or modulate tumor development. This condition has been observed in individuals with chronic states of immunosuppression, such as patients receiving treatment to prevent allograft rejection, those with acquired immunodeficiency (AIDS) and individuals with congenital immune disorders, which generally are at a higher risk of developing cancer $(19,20)$.

Different guidelines have been proposed in order to establish the relationship between infectious agents and diseases (Tables II and III). The agents considered in this review are EBV, HPV, HBV, HCV, KSHV and HTLV-1, which through epidemiological studies and molecular biology analysis have been established as causative agents of cancer.

\section{Epstein-Barr virus (EBV)}

EBV is a ubiquitous double-stranded DNA human virus of the gammaherpesviridae subfamily. It infects approximately $95 \%$ of the population worldwide with a primary asymptomatic infection occurring within the first three years of life. When primary infection is delayed until adolescence or adulthood, it presents as infectious mononucleosis (23). After the primary infection, individuals remain as asymptomatic carriers. EBV is transmitted through saliva infecting the oropharyngeal epithelial cells, which are the first site of infection (24). After binding the C21 receptor, EBV internalizes the cell and remains latent. This event may immortalize the infected cell through the induction of permanent growth transformation $(25,26)$. EBV is etiologically linked to Burkitt's lymphoma (BL), which is a tumor with higher incidence in areas with endemic malaria and is associated with nasopharyngeal carcinoma (NPC), which has a higher incidence among salted fish consumers. EBV also causes 
Table II. Evans and Mueller guidelines.

1. Geographic distribution of viral infection should coincide with that of the tumor, adjusting for the presence of known cofactors.

2. Presence of viral markers should be higher in case subjects than in matched control subjects.

3. Viral markers should precede the tumor, with a higher incidence of tumors in persons with markers than those without.

4. Prevention of viral infection should decrease tumor incidence.

Suggested epidemiologic guidelines:

1. Virus should be able to transform human cells in vitro.

2. Viral genome should be demonstrated in tumor cells, not in normal cells.

3. Virus should be able to induce the tumor in an experimental animal.

Suggested epidemiologic guidelines to support the etiologic role of a virus as cause of cancer (21).

Table III. Hill criteria for causality.

1. Strength of association virus-tumor.

2. Consistency

3. Specificity of association

4. Temporal relationship

5. Biologic gradient (dose-response)

6. Biologic plausability

7. Coherence

8. Experimental evidence

Sir Austin Bradford Hill, epidemiologic criteria to establish causation between disease and an environmental factor (22).

post-transplant lymphomas and is linked to Hodgkin's disease (27-29).

The EBV genome contains genes that encode for six nuclear proteins termed Epstein-Barr nuclear antigens: EBNA-1, EBNA-2, EBNA-3A, EBNA-3B, EBNA-3C and EBNA leader protein EBNA-LP. It also encodes three latent membrane proteins, LMP-1 LMP-2A, LMP-2B and Epstein-Barr nonpolyadenylated early RNAs (EBERs), which are abundant in latent cells. EBERs are used as markers to detect EBV infection (30). EBNA1 encodes a DNA binding protein essential for enabling replication of the viral episomal genome, being expressed in latent infected B cells and in all EBV-associated malignancies $(31,32)$. EBNA2 is a transcription factor that upregulates genes encoding for LMP1-LMP2 in B cells $(33,34)$. LMP-1 is a viral oncogene that resembles a cell-surface receptor. It prevents EBV-infected cells from apoptosis by the induction of anti-apoptotic proteins such as BCL-2, A20 and MCL-1 $(30,35,36)$. LMP1 activates the NF- $\mathrm{BB}$ transcription factor in B-lymphocytes and modulates epidermal growth factor receptor in epithelial cells $(37,38)$. LMP-1 is also implicated in three other signaling pathways, c-Jun $\mathrm{N}$-terminal kinase (JNK)-AP-1, mitogen activated protein kinase (p38/MAPK) and Janus kinase (JAK)-STAT, which regulate cell proliferation and apoptosis $(39,40)$. The role of EBNA3A, EBNA3B and EBNA3C is to regulate the expression of LMP-1. From this group of proteins, EBNA3C has shown to be essential in promoting immortalization of B-lymphocytes in presence of EBNA2 (41). EBNA-LP function allows the cell to re-enter the cell cycle by stimulating the activation of cyclin D2 (42). The expression of these genes varies according to the malignancy. In Burkitt's lymphoma and in post-transplant lymphoproliferative disease, EBNA1 and EBERs are expressed, while EBNA1, EBERs, LMP1 and LMP2 are expressed in Hodgkin's disease and NPC (43). This difference in gene expression is useful to understand the molecular aspects of each condition.

\section{Human papilloma virus (HPV)}

HPV is a small non-enveloped double-stranded DNA tumor virus. It causes a diverse range of epithelial lesions that transform from benign lesions such as anogenital warts, mild cervical dysplasia and recurrent respiratory papillomatosis, to pre-malignant and malignant lesions. Over 100 different types of HPV have been identified, but only some strains have demonstrated sufficient evidence to be designated as definitive human carcinogens. These strains are HPV-16 and HPV-18, which are considered 'high-risk' types. HPV-16 and HPV-18 account for approximately $70 \%$ of cervical and anal cancers worldwide. 'Low-risk' types are HPV-6 and HPV-11, accounting for approximately $90 \%$ of genital warts (44-48). HPV infects actively well-differentiated keratinocytes at the basal epithelial layer of the stratified squamous epithelium. It integrates into the host genome randomly and encodes for six non-structural viral regulatory proteins (E1, E2, E4, E5, E6 and E7) from the early region of the viral genome and two structural viral capsid proteins (L1 and L2) from the late region. The DNA integration process is preceded by the disruption of the E1/E2 regions, with the further deletion of the E2 region. As a consequence, E6 and E7 promoters are activated; E6 is the earliest expressed gene during HPV infection $(49,50)$. Only the early genes are transcribed after viral DNA replication. E6 binds with the tumor suppressor gene p53, inducing its degradation, which results in prevention of apoptosis (51-53). E7 has numerous interactions with cellular proteins involved in cell growth regulation, such as cyclin-dependent kinases (CDKs) and CDK inhibitors, but it interacts particularly with retinoblastoma suppressor protein $(\mathrm{Rb})$ by binding to the G0/G1-specific hypophosphorylated form of Rb, disrupting the $\mathrm{pRb} / \mathrm{E} 2 \mathrm{~F}$ complex and bypassing cell cycle arrest $(49,54-56)$. E5 protein binds with the platelet-derived growth factor $B$ receptor, promoting a sustained mitogenic signal (57). These events are synergistic and lead to deregulation of cell growth with the convenient inhibition of apoptosis, which allows for the accumulation of mutations.

The etiologic role of HPV upon cervical cancer has been well established. Strategies to prevent HPV and cervical cancer 
have been relying on prompt diagnosis and treatment. Recently, the quadrivalent and bivalent vaccines have been approved by the FDA. They are recombinant vaccines made of viruslike-particles (VLPs) derived from the L1 capsid protein of HPV types $6,11,16$ and 18 for the quadrivalent vaccine; 16 and 18 for the bivalent vaccine respectively. They mimic the HPV virus, although they lack the viral DNA content $(58,59)$. These HPV vaccines are expected to have a significant impact on HPV infection and cervical cancer incidence in the future.

\section{Hepatitis B virus (HBV) and hepatitis C virus (HCV)}

HBV and HCV are hepatotropic viruses that can cause both acute and chronic hepatic infections. Once these viruses bypass the immune response they may establish a chronic active hepatitis, which is known to be a major risk factor for developing hepatocellular carcinoma (HCC) in humans (60). These hepatotropic viruses are responsible for $80-90 \%$ of $\mathrm{HCC}$ cases worldwide. HCC arises most frequently in HBVand $\mathrm{HCV}$-induced cirrhotic livers, being most commonly associated with alcohol use in HCV infection (61). HBV infections in adults are usually cleared. In contrast, when HBV infection occurs early in life, it tends to become persistent $(62,63)$. These liver-tropic viruses have different biological properties; nevertheless, they share pathogenic mechanisms of chronic infection induction.

HBV is a small circular double-stranded DNA, which shares with the retroviruses the reverse transcription system. It may integrate into the cellular DNA, at random sites. When HBV-DNA integrates, it may target genes involved in cellular signaling pathways as sites of viral integration, such as the hTERT pathway $(64,65)$. HBV DNA has also been found integrated next to $\mathrm{v}$-erb-A which is an oncogene expressed inappropriately in HCC-cases (66). HBV DNA integration may cause chromosomal deletions, as found at the chromosomal region 17p11.2-12 causing the loss of the p53 gene (67). HBV DNA integration may cause disruptions or translocations, resulting in genetic instability $(68,69)$. The HBV genome has itself some oncogenic activities, expressing from integrated HBV the X gene (HBx), which seems to contribute indirectly to carcinogenesis by activating pathways such as mitogenactivated protein kinase (MAPK), c-jun $\mathrm{N}$-terminal kinase (JNK), protein kinase C (PKC), phosphatidylinositol 3-kinase (PI 3-kinase), protein kinase B (PKB/Akt) and JAK/STAT signaling cascades (70-73). It disrupts p53 pathway and alters the expression level of the retinoblastoma gene $(\mathrm{Rb})$, affecting cell cycle progression (74). HBx is not considered a direct transforming gene and therefore, the tumor induction mechanism of HBV is believed to be indirect.

$\mathrm{HCV}$ is a single-stranded RNA virus related to the flaviviridae family. It has been recognized as a post-transfusion transmitted cause of hepatitis and in recent years among injecting-drug users (75). HCV has a marked genetic variability given by its mixed population of heterogeneous HCV-RNA molecules designated quasispecies, which provide HCV with many immunological variants that permit the virus to escape the host immunity and persist as a chronic liver infection $(76,77)$. Studies have been made in order to determine the oncogenic properties of $\mathrm{HCV}$ in liver cells. An in vitro study has shown that $\mathrm{HCV}$ exerts its influence upon cell progression through the phosphorylation of RNA-regulated serine/threonine protein kinase (PKR), deregulating $\mathrm{G} 2 / \mathrm{M}$ phase and serving as a pathway for $\mathrm{HCV}$ to evade the antiviral effect of interferons (INs) (78). HCV lacks the capacity to integrate itself into the host genome and does not carry oncogenes. Instead, it possesses an indirect mechanism of carcinogenesis based on chronic liver damage, inflammation and cellular regeneration.

\section{Human herpes virus 8 (HHV-8)}

Human herpes virus 8 (HHV-8), also referred to as Kaposi's sarcoma-associated herpes virus (KHSV), is a double-stranded DNA virus classified in the Rhadinovirus genus, which belongs to the $\gamma$ - 2 herpesviridae sub-family. KHSV/HHV-8 is the etiological cause of Kaposi's sarcoma (KS). It is sexually transmitted remaining latent with the possibility of reactivation in immunocompromised individuals. KHSV/HHV-8 is a multifocal angioproliferative disease, commonly manifested as a cutaneous lesion. It is also associated with other proliferative disorders such as primary effusion lymphoma (PEL), and multicentric Castleman's disease (MCD) (79-81). There are four major forms of KS: the first type is the classic form, which is present in Mediterranean individuals. The second form consists in the association between KS and AIDS, where patients commonly present with disseminated KS. The third form is the endemic type and the fourth is the iatrogenic type, which occurs in individuals receiving immunosuppressive therapy (82). KHSV/HHV-8 establishes latent infection in the host, persisting episomally in B-lymphocytes. KSHV has a latent and a lytic phase. During the latent phase, it evades the immune system, persisting in the host cell having a restricted expression of genes (83). During lytic replication, viral proteins are produced unrestrictedly. KSHV produces a variety of immunomodulatory proteins with paracrine properties (84). KSHV contains several gene products with transforming properties among the most important are the viral G-protein coupled receptor (vGPCR), which is an IL-8 receptor analog and vIL-6, which modulates cell growth. The K1 protein can induce VEGF expression, while the v-cyclin and v-Bcl-2 proteins may inhibit apoptosis. They activate pathways controlling cellular growth, angiogenesis and inhibition of apoptosis such as the PI3K MAPK family Jak/STAT and nuclear factor- $\kappa \mathrm{B}(\mathrm{NF}-\kappa \mathrm{B})$ signaling pathway $(85,86)$. These proteins have shown transforming properties in vitro and in transgenic mice. However, HKSV gene products transforming properties still remain to be fully elucidated (87).

\section{Human T-cell leukemia virus type-1 (HTLV-1)}

HTLV-1 was the first human retrovirus described to be associated with malignancy (88). HTLV-1 is a T-cell tropic virus, which after infection promotes $\mathrm{T}$-cell activation and proliferation (89). It causes adult T-cell leukemia (ATL) and progressive myelopathy (HAM). The transmission of HTLV-1 occurs through sexual contact and mother-to-infant infection (90). HTLV-1 is a single-stranded RNA virus that contains retroviral genes encoding for the core proteins (gag), reverse transcriptase (pol), surface glycoprotein for receptor binding (env) and transcriptional activator (tax) genes (91). After 
infection it is reversely transcribed into a double-stranded DNA using genomic RNA as a template; subsequently, it is integrated randomly into the host chromosome without producing insertional mutagenesis. HTLV-1 contains a unique region called $\mathrm{pX}$, encoding for the Tax protein considered to be an oncoprotein. Tax is the product of a doubly spliced mRNA whose functions are to promote viral and gene expression through the activation of transcription factors such as the responsive element binding (CREB), nuclear factor $-\kappa \mathrm{B}(\mathrm{NF}-\kappa \mathrm{B})$, serum responsive factor $(\mathrm{SRF})$ and activator protein-1 (AP-1) transcription factors, with the further modification of the signal transduction (92). Tax has a direct effect upon the mitotic arrest defective protein (MAD1) altering mitotic checkpoints causing aneuploidy. It also causes interference with DNA repair mechanisms by repressing the activity of genes such as DNA B-polymerase (93). Tax can cause resistance of apoptosis through the activation of NF- $\mathrm{\kappa B}$ promoter and the indirect function impairment of P53 (94). It interacts indirectly with $\mathrm{Rb}$ through the activation of the cyclin D/CDK4-6 complexes, hyperphosphorylating $\mathrm{Rb}$ and consequently promoting the progression of the cell cycle (Fig. 2) (95).

\section{Conclusion}

Infectious agents particularly viruses, may play an important role contributing to human cancer development. Substantial evidence has been gathered through studies supporting their tumorigenic effects; however, it is commonly difficult to prove their association with cancer since many factors between the host and the virus have to interact in order to create the proper scenario for cancer to develop. The agents mentioned in this review have been the best established as human tumor viruses. There are other agents under investigation that could potentially be part of this group and others yet to be discovered. Tumor viruses have not only given us insight into cancer and cell biology through their transforming properties, but they have also given us the opportunity to design innovative targeted cancer therapies based on the pathways disrupted by the transforming viral genes. An example of this are the gene-based therapies currently under development, which are meant to be more specific than the classical ones. Another innovative therapy to be considered in the future might be the use of stem cells; studies have been conducted in other pathological conditions including cancer with promising results (96). In general, prevention remains the most effective approach against viral infection and towards cancer risk reduction. Vaccine strategies seem to be the best approach for some of these viral infections, such as the HBV and the recently released HPV vaccine. Nevertheless, additional information still needs to be gathered to understand the synergistic properties of cofactors and viral carcinogenic mechanisms.

\section{Acknowledgements}

The authors thank Professor Alessandra Renieri from the University of Siena, Dr Gaetano Romano and Ms. Marie Basso for their precious comments and advice in the preparation of the manuscript. This work has been funded by NIH, Sbarro Health Research Organization (SHRO), www.shro.org and Within3-PrometeoNetwork www.within3.com, www. prometeonetwork.com.

\section{References}

1. Gan DD, Macaluso M, Cinti C, Khalili K and Giordano A: How does a normal human cell become a cancer cell. J Exp Clin Cancer Res 4: 509-516, 2003.

2. Karakosta A, Golias Ch, Charalabopoulos A, Batistatou A and Charalabopoulos K: Genetic models of human cancer as a multistep process. Paradigm models of colorectal cancer, breast cancer: and chronic myelogenous and acute lymphoblastic leukaemia (review). J Exp Clin Cancer Res 24: 505-513, 2005.

3. Parkin DM: The global health burden of infection-associated cancers in the year 2002 (review). Int J Cancer 118: 3030-3044, 2006.

4. De Visser KE and Coussens LM: The interplay between innate and adaptive immunity regulates cancer development. Cancer Immunol Immunother 54: 1143-1152, 2005.

5. Campoli M, Ferrone S, Zea AH, Rodriguez PC and Ochoa AC: Mechanisms of tumor evasion. Cancer Treat Res 123: 61-88, 2005.

6. Hofseth LJ, Hussain SP, Wogan GN and Harris CC: Nitric oxide in cancer and chemoprevention. Free Radic Biol Med 34: 955-968, 2003.

7. Lirk P, Hoffmann G and Rieder J: Inducible nitric oxide synthasetime for reappraisal. Curr Drug Targets Inflamm Allergy 1: 89-108, 2002.

8. Szabo C and Ohshima H: DNA damage induced by peroxynitrite: subsequent biological effects. Nitric Oxide 1: 373-385, 1997.

9. Mills KH: Regulatory T cells: friend or foe in immunity to infection? Nat Rev Immunol 4: 841-855, 2004.

10. Fehervari $\mathrm{Z}$ and Sakaguchi S: CD4 ${ }^{+}$Tregs and immune control. J Clin Invest 114: 1209-1221, 2004.

11. Suvas S, Azkur AK, Kim BS, Kumaraguru U and Rouse BT: $\mathrm{CD} 4{ }^{+} \mathrm{CD} 25^{+}$regulatory $\mathrm{T}$ cells control the severity of viral immuno-inflammatory lesions. J Immunol 172: 4123-4132, 2004.

12. Schottenfield D and Beebe-Dimmer JL: Advances in cancer epidemiology: understanding causal mechanisms and the evidence for implementing interventions. Ann Rev Public Health 26: 37-60, 2005.

13. Tyler KL and Fields BN: Pathogenesis of viral infections. In: Fields Virology. 3rd edition. Fields BN, Knipe DM and Howley PM (eds). Lippincott-Raven Publishers, Philadelphia, PA, pp173-203, 1996.

14. Beral V and Newton R: Overview of the epidemiology of immunodeficiency-associated cancers. Monogr Natl Cancer Inst 23: 1-6, 1998.

15. Newton R, Beral V and Weiss R: Human immunodeficiency virus infection and cancer. Cancer Surv 33: 237-262, 1999.

16. Nevins JF and Vogt PK: Cell transformation by viruses. In: Fields Virology. 3rd edition. Fields BN, Knipe DM and Howley PM (eds). Lippincott-Raven Publishers, Philadelphia, PA, pp301-335, 1996.

17. Hunter T: Cooperation between oncogenes. Cell 64: 249-270, 1991

18. Yokota $\mathrm{J}$ and Sugimura T: Multiple steps in carcinogenesis involving alterations of multiple tumor suppressor genes. FASEB J 7: 20-25, 1993.

19. Diehl V, Hauch P and Harris N: Hodgkin's disease. In: Cancer: Principles and Practice of Oncology. De Vita VT, Hellman S and Rosenberg SA (eds). Lippincott Williams \& Wilkins, Philadelphia, PA, pp23-39, 2001.

20. Yarchoan R and Little RE: Immunosuppression-related malignancies. In: Cancer: Principles and Practice of Oncology. De Vita VT, Hellman S and Rosenberg SA (eds). Lippincott Williams \& Wilkins, Philadelphia, PA, p2575, 2001.

21. Evans AS and Mueller NE: Viruses and cancer: causal associations. Ann Epidemiol 1: 71-92, 1990.

22. Hill AB: Environment and disease: association of causation? Proc R Soc Med 58: 295-300, 1965.

23. Papesch $M$ and Watkins R: Epstein-Barr virus infectious mononucleosis. Clin Otolaryngol 26: 3-8, 2001.

24. Sixbey JW, Nedrud JG, Raab-Traub N, Hanes RA and Pagano JS: Epstein-Barr virus replication in oropharyngeal epithelial cells. N Engl J Med 310: 1225-1230, 1984.

25. Su IJ and Chen JY: The role of Epstein-Barr virus in lymphoid malignancies. Crit Rev Oncol Hematol 26: 25-41, 1997. 
26. Liebowitz D: Epstein-Barr virus and a cellular signaling pathway in lymphomas from immunosuppressed patients. N Engl J Med 338: 1413-1421, 1998

27. Jeannel D, Bouvier G and Huber A: Nasopharyneal carcinoma: an epidemiological approach to carcinogenesis. Cancer Surv 33: 125-155, 1999.

28. Raab-Traub N: Epstein-Barr virus, lymphoproliferative diseases and nasopharyngeal carcinoma. In: Microbes and Malignancy: Infection as a Cause of Human Cancers. Parsonnet J (ed). Oxford University Press, Oxford, UK, pp180-206, 1999.

29. Brooks LA, Crook T and Crawford DH: Epstein-Barr virus and lymphomas. Cancer Surv 33: 75-98, 1999.

30. Camilleri-Broct S, Camparo P, Mokhtari K, et al: Overexpression of Bcl-2, bcl-x and Bax in primary central nervous system lymphomas that occur in immunosuppressed patients. Mod Pathol 13: 158-165, 2000.

31. Wilson JB, Bell JL and Levine AJ: Expression of Epstein-Barr virus nuclear antigen-1 induces $B$ cell neoplasia in transgenic mice. EMBO J 15: 3117-3126, 1996.

32. Levitskaya J, Coram M, Levitsky V, et al: Inhibition of antigen processing by the internal repeat region of the Epstein-Barr virus nuclear antigen-1. Nature 375: 685-688, 1995.

33. Abbot SD, Rowe M, Cadwallader K, et al: Epstein-Barr virus nuclear antigen 2 induces expression of the virus-encoded latent membrane protein. J Virol 64: 2126-2134, 1990.

34. Zimber-Strobl U, Suentzenich KO, Laux G, et al: Epstein-Barr virus nuclear antigen 2 activates transcription of the terminal protein gene. J Virol 65: 425-423, 1991

35. Gregory CD, Dive C, Henderson S, Smith CA, Williams GT, Gordon $\mathrm{J}$ and Rickinson AB: Activation of Epstein-Barr virus latent genes protects human B cells from death by apoptosis. Nature 349: 612-614, 1991.

36. Laherty CD, Hu MM, Opipari AW, Wang F and Dixit VM: The Epstein-Barr virus LMP1 gene product induces A20 zinc finger protein expression by activating nuclear factor $\kappa \mathrm{B}$. J Biol Chem 267: 24157-24160, 1992.

37. Mosialos G, Birkenbach M, Yalamanchili R, van Arsdale T, Ware $\mathrm{C}$ and Kieff E: The Epstein-Barr virus transforming protein LMP1 engages signaling proteins for the tumor necrosis factor receptor family. Cell 80: 389-399, 1995.

38. Eliopoulos AG, Stack M, Dawson CW, et al: Epstein-Barr virus encoded LMP1 and CD40 mediate IL-6 production in epithelial cells via and NF-кB pathway involving TNF-receptor-associated factors. Oncogene 14: 2899-2916, 1997.

39. Eliopoulos AG and Young LS: Activation of the c-Jun N-terminal kinase (JNK) pathway by the Epstein-Barr virus encoded latent membrane protein-1. Oncogene 16: 1731-1742, 1998.

40. Gires O, Kohlhuber F, Kilger E, et al: Latent membrane protein 1 of Epstein-Barr virus interacts with JAK3 and activates STAT proteins. EMBO J 18: 3064-3073, 1999.

41. Zhao B and Sample CE: Epstein-Barr virus nuclear antigen $3 \mathrm{C}$ activates the latent membrane protein 1 promoter in the presence of Epstein-Barr virus nuclear antigen 2 through sequences encompassing an Spi-1/Spi-B binding site. J Virol 74: 5151-5160, 2000.

42. Cheng $G$ and Baltimore D: TANK, a co-inducer with TRAF2 of TNF- and CD40L-mediated NF- $\mathrm{KB}$ activation. Genes Dev 10: 963-973, 1996.

43. Cen H, Williams PA, McWilliams HP, Breinig MC, Ho M and McKnight JL: Evidence for restricted Epstein-Barr virus latent gene expression and anti-EBNA antibody response in solid organ transplant recipients with posttransplant lymphoproliferative disorders. Blood 81: 1393-1403, 1993.

44. Bernard HU: The clinical importance of the nomenclature, evolution and taxonomy of human papillomaviruses. J Clin Virol 32: S1-S6, 2005.

45. IARC. Human papillomaviruses. Monographs on the Evaluation of Carcinogenic Risks to Humans. Vol. 64. IARC, Lyon, pp1-378, 1995.

46. Munoz N, Bosch FX, De Sanjose S, et al: Epidemiologic classification of human papillomavirus types associated with cervical cancer. N Engl J Med 348: 518-527, 2003.

47. Bovicelli A, D'Andrilli G and Giordano A: Multidisciplinary International Conference on Gynecologic Cancer, Bologna, Italy, June 8-12, 2005. J Cell Physiol 208: 1-5, 2006.

48. Clifford GM, Smith JS, Plummer M, Munoz N and Franceschi S: Human papillomavirus types in invasive cervical cancer worldwide: a meta-analysis. Br J Cancer 88: 63-73, 2003.

49. Fehrmann F and Laimins LA: Human papillomaviruses: targeting differentiating epithelial cells for malignant transformation. Oncogene 22: 5201-5207, 2003
50. Francis DA, Schmid SI and Howley PM: Repression of the integrated papillomavirus E6/E7 promoter is required for growth suppression of cervical cancer cells. J Virol 74: 2679-2686, 2000

51. Scheffner M, Werness BA, Huibregtse JM, Levine AJ and Howley PM: The E6 oncoprotein encoded by human papillomavirus types 16 and 18 promotes the degradation of p53. Cell 63: 1129-1136, 1990 .

52. Mythily DV, Krishna S and Tergaonkar V: Pleiotropic effects of human papillomavirus type 16 . E6 oncogene expression in human epithelial cell lines. J Gen Virol 80: 1707-1713, 1999.

53. Klingelhutz AJ, Foster SA and McDougall JK: Telomerase activation by the E6 gene product of human papillomavirus type 16. Nature 380: 79-82, 1996

54. Dyson $\mathrm{N}$ : The regulation of $\mathrm{E} 2 \mathrm{~F}$ by $\mathrm{Rb}$-family proteins. Genes Dev 12: 2245-2262, 1998.

55. Cage JR, Meyers C and Wettstein FO: The E7 proteins of the nononcogenic human papillomavirus type $6 \mathrm{~b}$ (HPV-6b) and of the oncogenic HPV-16 differ in retinoblastoma protein binding and other properties. J Virol 64: 723-730, 1990.

56. Imai Y, Matsushima Y, Sugimura T and Terrada M: Purification and characterization of human papillomavirus type $16 \mathrm{E} 7$ protein with preferential binding capacity to the underphosphorylated form of retinoblastoma gene product. J Virol 65: 4966-4972, 1991.

57. Di Maio D, Lai CC and Klein O: Virocrine transformation: the intersection between viral transforming proteins and cellular signal transduction pathways. Annu Rev Microbiol 52: 397-421, 1998.

58. Villa LL, Costa RL, Petta CA, et al: Prophylactic quadrivalent human papillomavirus (types 6, 11, 16, and 18) L1 virus-likeparticle vaccine in young women: a randomized double-blind placebo-controlled multicenter phase II efficacy trial. Lancet Oncol 6: 271-278, 2005.

59. Harper DM, Franco EL, Wheeler CM, et al: Sustained efficacy up to 4.5 years of a bivalent L1 virus-like particle vaccine against human papillomavirus types 16 and 18: follow-up from a randomized control trial. Lancet 367: 1247-1255, 2006.

60. IARC Hepatitis viruses. Monographs on the Evaluation of Carcinogenic Risks. Vol. 59. IARC, Lyon, 1994.

61. Fattovich G, Stroffolini T, Zagni I and Donato F: Hepatocellular carcinoma in cirrhosis: incidence and risk factors. Gastroenterology 127: S27-S34, 2004.

62. Buendia MA: Hepatitis B viruses and hepatocellular carcinoma Adv Cancer Res 59: 167-226, 1992.

63. Hollinger FF: Hepatitis B virus. In: Fields Virology 3rd. Vol. 2 Fields GN, Knipe DM, Howley PM, Chanock RM, Melnick JL, Monath TP, Roizman B and Straus SE (eds). Lippincott-Raven, Philadelphia PA, pp2739-2807, 1990

64. Hino O, Tabata S and Hotta Y: Evidence for increased in vitro recombination with insertion of human hepatitis $B$ virus DNA. Proc Natl Acad Sci USA 88: 9248-9252, 1991.

65. Paterlini-Brechot P, Saigo K, Murakami Y, et al: Hepatitis B virus-related insertional mutagenesis occurs frequently in human liver cancers and recurrently targets human telomerase gene. Oncogene 22: 3911-3916, 2003.

66. Dejean A, Bougueleret L, Grzeschik KH and Tiollais P: Hepatitis B virus DNA integration in a sequence homologous to $\mathrm{v}$-erb-A and steroid receptor genes in a hepatocellular carcinoma. Nature 322: 70-72, 1986.

67. Slagle BL, Zhou YZ and Butel JS: Hepatitis B virus integration event in human chromosome $17 \mathrm{p}$ near the p53 gene identifies the region of the chromosome commonly deleted in virus-positive hepatocellular carcinomas. Cancer Res 51: 49-54, 1991.

68. Matsubara $\mathrm{K}$ and Tokino $\mathrm{T}$ : Integration of hepatitis $\mathrm{B}$ virus DNA and its implications for hepatocarcinogenesis. Mol Biol Med 7: 243-260, 1990.

69. Robinson WS: Hepatitis B virus and hepatocellular carcinoma In: Microbes and Malignancy: Infection as a Cause of Human Cancers. Parsonnet J (ed). Oxford University Press, Oxford, pp232-266, 1999.

70. Natoli G, Avantaggiati ML, Chirillo P, et al: Modulation of intracellular signal transduction pathways by the hepatitis $B$ virus transactivator $\mathrm{pX}$. J Hepatol 22: 14-20, 1995

71. Lee YH and Yun Y: HBx protein of hepatitis B virus activates Jak1-STAT signaling. J Biol Chem 273: 25510-25515, 1998

72. Diao J, Khine AA, Sarangi F, et al: X protein of hepatitis B virus inhibits Fas-mediated apoptosis and is associated with up-regulation of the SAPK/JNK pathway. J Biol Chem 276: 8328-8340, 2001 
73. Lee YI, Kang-Park S, Do SI and Lee YI: The hepatitis B virus-X protein activates a phosphatidylinositol 3-kinase-dependent survival signaling cascade. J Biol Chem 276: 16969-16977, 2001.

74. Edamoto Y, Hara A, Biernat W, et al: Alterations of RB1, p53 and Wnt pathways in hepatocellular carcinomas associated with hepatitis C, hepatitis B and alcoholic liver cirrhosis. Int J Cancer 106: 334-341, 2003.

75. Bréchot C: Hepatitis C virus: molecular biology and genetic variability. In: Acute and Chronic Liver Diseases. Schmid R (ed). Kluwer Academic Publishers, Basel, pp35-57, 1996.

76. Ferns X, Purcell RH and Burkh J: Quasispecies in viral persistence and pathogenesis of hepatitis $\mathrm{C}$ virus. Trends Microbiol 7: 402-410, 1999.

77. Alter MJ, Kruszon-Moran D, Nainan OV, et al: The prevalence of hepatitis C virus infection in the United States. 1988 through 1994. N Engl J Med 341: 556-562, 1999.

78. Alisi A, Mele R, Spaziani A, Tavolaro S, Palescandolo E and Balsano C: Thr 446 phosphorylation of PKR by $\mathrm{HCV}$ core protein deregulates G2/M phase in HCC cells. J Cell Biol 205: 25-31, 2005.

79. Dupin N, Fisher C, Kellam P, et al: Distribution of human herpesvirus- 8 latently infected cells in Kaposi's sarcoma, multicentric Castleman's disease, and primary effusion lymphoma. Proc Natl Acad Sci USA 96: 4546-4551, 1999.

80. Xchulz TF: Kaposi's sarcoma-associated herpesvirus (human herpesvirus-8). J Gen Virol 79: 1573-1591, 1998.

81. Cohen A, Wolf DG, Guttman-Yassky E and Sarid R: Kaposi's sarcoma-associated herpesvirus: clinical, diagnostic, and epidemiological aspects. Crit Rev Clin Lab Sci 42: 101-103, 2005.

82. Antman K and Chang Y: Kaposi's sarcoma. N Engl J Med 342: 1027-1038, 2000.

83. Ballestas ME, Chatis PA and Kaye KM: Efficient persistence of extrachromosomal KSHV DNA mediated by latency-associated nuclear antigen. Science 71: 641-644, 1999.

84. Pati S, Cavrois M, Guo HG, Foulke JS Jr, Kim J, Feldman RA and Reitz M: Activation of NF-kappaB by the human herpesvirus 8 chemokine receptor ORF74: evidence for a paracrine model of Kaposi's sarcoma pathogenesis. J Virol 75: 8660-8673, 2001.
85. Cheng EH, Nicholas J, Bellows DS, Hayward GS and Guo HG: A Bcl-2 homolog encoded by Kaposi sarcoma-associated virus, human herpesvirus 8 , inhibits apoptosis but does not heterodimerize with Bax or Bak. Proc Natl Acad Sci USA 94: 690-694, 1997.

86. Burger M, Hartmann T, Burger JA and Schraufstatter I: KSHVvGPCR and CXCR2 transforming capacity and angiogenic responses are mediated through a JAK2-STAT3-dependent pathway. Oncogene 24: 2067-2075, 2005.

87. Dadke D, Fryer BH, Golemis EA and Field J: Activation of p21activated kinase 1-nuclear factor kappaB signaling by Kaposi's sarcoma-associated herpes virus $\mathrm{G}$ protein-coupled receptor during cellular transformation. Cancer Res 63: 8837-8847, 2003.

88. Gallo RC: The first human retrovirus. Sci Am 255: 88-98, 1986

89. Hinuma Y, Nagata K, Hanaoka M, et al: Adult T-cell leukemia: antigen in an ATL cell line and detection of antibodies to the antigen in human sera. Proc Natl Acad Sci USA 78: 6476-6480, 1981 .

90. Kashiwagi K, Furusyo N, Nakashima H, Kubo N, Kinukawa N, Kashiwagi S and Hayashi J: A decrease in mother-to-child transmission of human T lymphotropic virus type I (HTLV-1) in Okinawa, Japan. Am J Trop Med Hyg 70: 158-163, 2004.

91. Matsuoka M: Human T-cell leukemia virus type I and adult T-cell leukemia. Oncogene 22: 5131-5140, 2003.

92. Alefantis T, Barmak K, Harhaj EW, Grant C and Wigdahl B: Characterization of a nuclear export signal within the human $\mathrm{T}$ cell leukemia virus type I transactivator protein Tax. J Biol Chem 278: 21814-21822, 2003.

93. Grassmann R, Aboud M and Jeang KT: Molecular mechanisms of cellular transformation by HTLV-1 Tax. Oncogene 24: 5976-5985, 2005.

94. Baeuerle PA and Baltimore D: NF-кB: Ten years after. Cell 87: 13-20, 1996.

95. Haller K, Wu Y, Derow E, Schmitt I, et al: Physical interaction of human T-cell leukemia virus type 1 Tax with cyclin-dependent kinase 4 stimulates the phosphorylation of retinoblastoma protein. Mol Cell Biol 22: 3327-3338, 2002.

96. Giordano A, Galderisi U and Marino IR: From the laboratory bench to the patient's bedside: an update on clinical trials with mesenchymal stem cells. J Cell Physiol 211: 27-35, 2007. 